\title{
Trail following Learning by Young Myrmica rubra Workers (Hymenoptera, Formicidae)
}

\author{
Marie-Claire Cammaerts \\ Faculté des Sciences, DBO, CP 160/12, Université Libre de Bruxelles, 50 Avenue Franklin Roosevelt, 1050 Bruxelles, Belgium \\ Correspondence should be addressed to Marie-Claire Cammaerts; mtricot@ulb.ac.be
}

Received 31 July 2013; Accepted 1 September 2013

Academic Editors: F. C. Abdalla, W. Brown, P. A. Calatayud, and J. Rojas

Copyright ( 2013 Marie-Claire Cammaerts. This is an open access article distributed under the Creative Commons Attribution License, which permits unrestricted use, distribution, and reproduction in any medium, provided the original work is properly cited.

\begin{abstract}
Ants use chemical trails, laid down on the ground, for recruiting congeners and helping them to return to the nest. The present work shows that young ants, less than one year old, though obviously reacting to the trail pheromone, are unable to efficiently follow a trail. These young ants begin to better walk along a trail when being in presence of trail following older congeners. Later on, they can by themselves rather efficiently follow a trail. Queens removed from their nest correctly move along a trail. The knowledge of the trail pheromone is thus native, while the trail following behavior is both partly native and partly learned. The latter learning is rapid and may be induced and/or enhanced by older trail following nestmates.
\end{abstract}

\section{Introduction}

An ant colony has a highly structured social organization. The individuals perform many complex tasks such as caring of the brood and queens, foraging and navigating on their area, collecting food, recruiting congeners, defending the colony, relocating the nest, and building a nest [1]. Such a social life is regulated by chemical, visual, tactile, and acoustic signals such as an alarm pheromone [2], area marking substances [3-5], a trail pheromone [6], individual cuticular odors [7], learned visual elements [8-10], antennal contacts [11], and sounds [12].

Recently, we observed that young ants, about 3 months old, know none of these signals and cannot accomplish any social tasks (returning to their nest, entering the nest, using the trail pheromone, making a trophalaxy, and so on [13]). So, after having largely studied the know-how of ant foragers [14], we actually aimed to examine how young ants acquire all these cognitive abilities.

It has already been proved that young ants early know their nest odor thanks to habituation and/or imprinting [15]. Working on the species Myrmica rubra (Linnaeus, 1758), we showed that young workers become imprinted to their nest entrance odor and learn thereafter, thanks to operant conditioning, the visual aspects of such entrances [16]. Young $M$. rubra workers were also proved to be quickly imprinted to their specific foraging area odor in the course of their first outside trip [17]. We know that foragers learn, thanks to operant conditioning, different olfactory and visual elements which surround their nest and allow them to negotiate their way while foraging (references here above).

But how do young ants learn the trail pheromone odor and trail following behavior? In the ant species M. rubra, this pheromone is elaborated in the workers' poison gland [18] and is not emitted inside the nest. The young ants do not produce that pheromone and do not respond to it [19]. However, older ants' trail following behavior is very efficient [20].

The present work relates the experimental work performed to understand the ontogenesis of the ants' trail following behaviour.

\section{Material and Methods}

2.1. Collection and Maintenance of the Ants. The experiments were performed on the foragers and the young ants of two large colonies of M. rubra (labeled I, II) as well as on the queen of colony II and of two other smaller colonies (labeled III, IV). All these colonies were collected on grassland, at Marchin (Condroz, Belgium). The large colonies contained a queen, brood, and about 500 workers. From March to May 2012, several workers emerged and were thus about 9 to 10 months old 


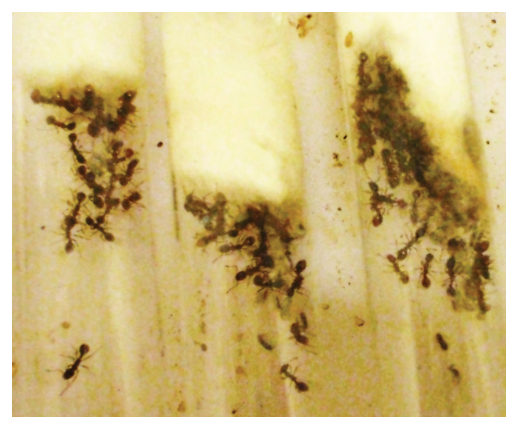

(a)

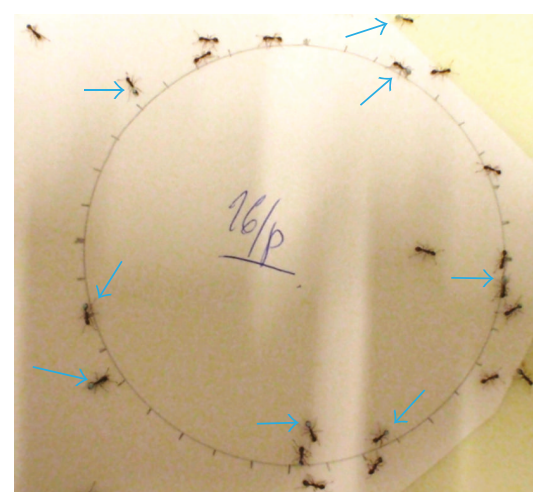

(d)

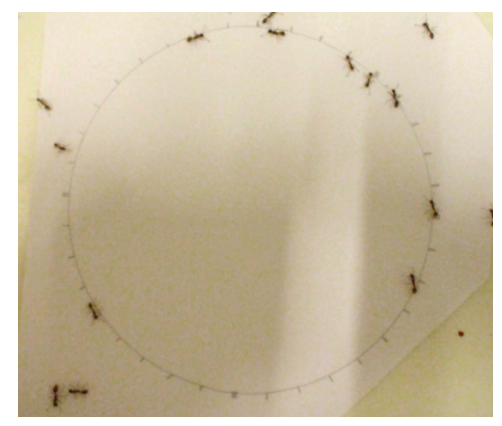

(b)

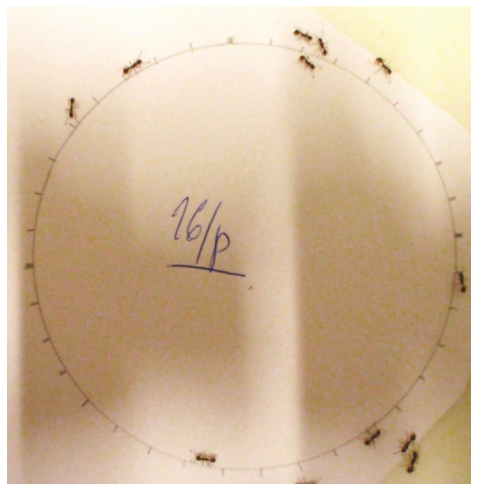

(e)

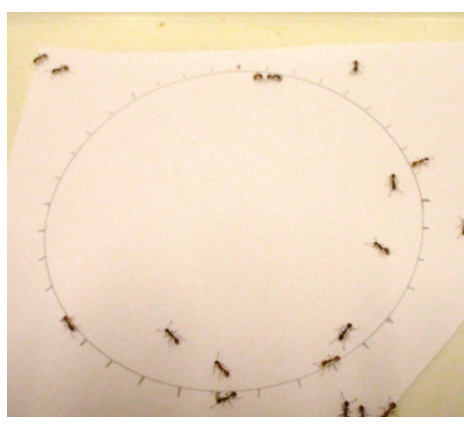

(c)

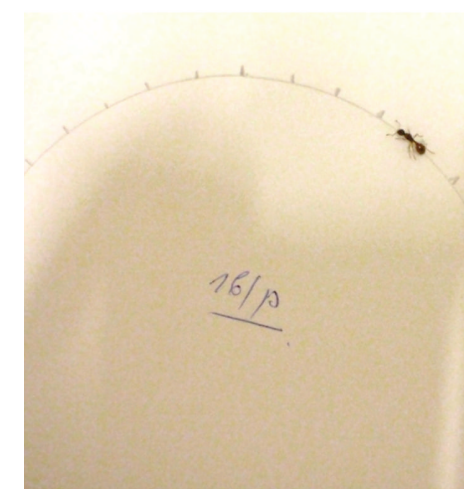

(f)

Figure 1: (a) Young workers and a few older ones inside of nest I. (b) Foragers on a trail (1 poison gland/cf. $(R=5 \mathrm{~cm})$ ); they walked on the trail. (c) Naive young workers on an identical trail; they did not correctly walk on the trail. (d) Marked in blue foragers (blue arrows) and young workers, together, on a trail; foragers followed the trail and young ants also, though less efficiently. (e) Young ants on a trail, after having been in presence of trail following foragers; they walked rather well on the trail. (f) A queen on a trail; she followed the trail.

in February 2013, when the experiment was undertaken. They were not as dark as older workers and expected to live for up to three years [21]. The colonies were maintained in the laboratory in artificial nests made of one to three glass tubes halffilled with water and a cotton-plug separating the ants from the water (Figure 1(a)). The glass tubes were deposited in trays $(42 \mathrm{~cm} \times 27 \mathrm{~cm} \times 7 \mathrm{~cm})$, the sides of which were covered with talc. The trays served as foraging areas, food being delivered in them. The ants were fed with sugar water provided ad libitum in a small glass tube plugged with cotton and with cut Tenebrio molitor served twice a week on a glass slide. Temperature was maintained at $20^{\circ} \pm 2^{\circ} \mathrm{C}$, humidity at about $80 \%$, this remaining constant over the course of the experimentation. The lighting had a constant intensity of 330 lux when caring for the ants (e.g., providing food and renewing nesting tubes), training the ants, and testing them. During the other time periods, the lighting was dimmed to 110 lux.

2.2. Quantification of the Ants' Trail following Behavior. The trail pheromone of Myrmica ants being produced by the workers' poison gland, ten of these glands were isolated in $0.5 \mathrm{~mL}(500 \mu \mathrm{L})$ hexane and stored for $15 \mathrm{~min}$ at $-25^{\circ} \mathrm{C}$. To perform one experiment, $0.05 \mathrm{~mL}(50 \mu \mathrm{L})$ of the solution was deposited, using a normograph pen (a pen used for drawing, hexane extract being poured inside the pen instead of ink), on a circle $(R=5 \mathrm{~cm})$ pencil drawn on a piece of white paper and divided into 10 ang. deg. arcs (Figures 1(b)-1(f)).
One minute after being prepared, the piece of paper with the artificial trail was placed in a small tray (an experimental tray: $31 \mathrm{~cm} \times 17 \mathrm{~cm} \times 7 \mathrm{~cm}$ ) which borders have been covered with talc and into which the ants to be tested, removed from their colony, have been previously set (see below "experimental protocol"). When an ant came into contact with the trail, its movement was observed. Its response to the trail pheromone was assessed by the number of $10 \mathrm{ang}$. deg. arcs it walked without departing from the trail, even if it turned back on the trail (Figures 1(b)-1(f)). If an ant turned back on its way when being in front of the trail, its response was assessed as "zero arcs walked." When an ant crossed the trail without following it, its response equaled "one walked arc." Before testing foragers as well as young ants on a trail, they were observed on an identical but blank circumference, that is, imbibed with $50 \mu \mathrm{L}$ of pure hexane, and the control numbers of walked arcs were so obtained. For each experiment (the control ones and the test ones made on old ants, on young workers, and on queens), 40 individuals' trajectories were quantified. We so obtained 40 values of number of walked arcs for each experiment. Let us precise that ants deposit a trail only after having found food or a new nest site and never while walking along a trail away from their nest.

2.3. Statistical Analysis. For each experiment (control ant test ones), the median and quartiles of the distribution of the 40 obtained numbers of walked arcs were documented (Table 1). 
TABLE 1: Trail following of foragers, naïve young ants, the two kinds of ants set together, young ants again, alone, after 20, 2, or 24 hours, and queens. Thirty foragers and 30 young ants from nest I, 20 foragers and 20 young ants from nest II, and 3 queens were used. The ants were tested on circumferences $(R=5 \mathrm{~cm})$ either blank (pure hexane) or imbibed with 1 poison gland extract, this containing the trail pheromone. Each time, 40 values of trail following behavior were recorded, an individual having thus the possibility of making several trajectories on the trail. The obtained distributions of the 40 values were characterized by their median and quartiles and compared to one another using the nonparametric $\chi^{2}$ test [22]. Experimental details are given in the "Material and Methods" section and statistical results in the "Results" section.

\begin{tabular}{|c|c|c|c|c|c|c|c|c|}
\hline \multirow{3}{*}{ Numbers of walked arcs } & \multicolumn{4}{|c|}{ Foragers } & \multicolumn{4}{|c|}{ Naïve young ants } \\
\hline & \multicolumn{2}{|c|}{ Hexane } & \multicolumn{2}{|c|}{1 gland/trail } & \multicolumn{2}{|c|}{ Hexane } & \multicolumn{2}{|c|}{1 gland/trail } \\
\hline & Nest I & Nest II & Nest I & Nest II & Nest I & Nest II & Nest I & Nest II \\
\hline 0 & 1 & 2 & 0 & 0 & 5 & 3 & 1 & 8 \\
\hline 1 & 27 & 25 & 1 & 0 & 29 & 32 & 22 & 14 \\
\hline $2-3$ & 11 & 12 & 0 & 3 & 6 & 5 & 13 & 14 \\
\hline $4-5$ & 0 & 1 & 1 & 2 & & & 3 & 3 \\
\hline $6-8$ & 1 & & 5 & 5 & & & 0 & 1 \\
\hline $9-12$ & & & 5 & 8 & & & 1 & \\
\hline $13-20$ & & & 17 & 15 & & & & \\
\hline $21-30$ & & & 6 & 6 & & & & \\
\hline $31-50$ & & & 4 & 1 & & & & \\
\hline$>50$ & & & 1 & & & & & \\
\hline Median & 1.0 & 1.0 & 16.0 & 14.5 & 1.0 & 1.0 & 1.0 & 1.0 \\
\hline \multirow[t]{4}{*}{ Quartiles } & $1-2$ & $1-2$ & $10.8-23.5$ & $8.8-18.5$ & $1-1$ & $1-1$ & $1-2$ & $1-2$ \\
\hline & \multicolumn{4}{|c|}{ Marked foragers + young ants } & \multicolumn{3}{|c|}{ Young alone again } & \multirow{3}{*}{ Queens } \\
\hline & \multicolumn{2}{|c|}{ Foragers } & \multicolumn{2}{|c|}{ Young ants } & \multicolumn{3}{|c|}{ After } & \\
\hline & Nest I & Nest II & Nest I & Nest II & $20 \mathrm{~h}(\mathrm{I})$ & $2 \mathrm{~h}(\mathrm{II})$ & $24 \mathrm{~h}$ (II) & \\
\hline 0 & 0 & 0 & 0 & 0 & 0 & 0 & 0 & 0 \\
\hline 1 & 0 & 0 & 3 & 3 & 3 & 5 & 0 & 2 \\
\hline $2-3$ & 0 & 0 & 7 & 4 & 3 & 8 & 3 & 10 \\
\hline $4-5$ & 1 & 0 & 9 & 10 & 2 & 3 & 8 & 7 \\
\hline $6-8$ & 2 & 3 & 11 & 5 & 11 & 7 & 3 & 8 \\
\hline $9-12$ & 8 & 9 & 6 & 9 & 7 & 6 & 7 & 7 \\
\hline $13-20$ & 14 & 23 & 4 & 9 & 10 & 4 & 9 & 1 \\
\hline $21-30$ & 12 & 5 & & & 5 & 4 & 6 & 1 \\
\hline $31-50$ & 2 & & & & & 2 & 4 & 1 \\
\hline$>50$ & & & & & & 1 & & 3 \\
\hline Median & 16.0 & 17.0 & 6.5 & 8.0 & 10.0 & 7.5 & 12.0 & 6.0 \\
\hline Quartiles & $12-23$ & $12-20$ & $4-9.3$ & $4-11.3$ & $6-18$ & $3-17$ & 5-20.3 & $3-10$ \\
\hline
\end{tabular}

Such an assessment was used because the numbers of arcs walked along a trail are not normally distributed (many ants walk along a few arcs; only a few ones walk along more than twenty arcs) (e.g., [18]). The obtained distributions could be compared to one another using the nonparametric $\chi^{2}$ test [22], the level of probability being set at 0.05 .

2.4. Experimental Protocol. The different experiments were made first on 30 foragers and 30 young ants of nest I, then on 20 foragers and 20 young ants of nest II, and finally on 3 queens (of nests II, III, and IV). These experiments and their results are however related according to the kind of experiment performed (see Section 3 and Table 1).

(i) For nest I, then nest II, the following kinds of experiment were made:

(a) foragers were tested on pure hexane,

(b) foragers were tested on a trail,

(c) young ants were tested on pure hexane, (d) young ants were tested on a trail,

(e) foragers were marked in blue, set together with young ants in the small experimental tray, and the two kind of ants were tested, at the same time, on a trail,

(f) later on, the young ants, that had been in presence of trail following foragers, were tested again on a trail,

(ii) Finally, three queens of three different colonies were tested, one by one, on a trail.

As soon as an experiment was finished, the tested individuals were gently put back in their colony, exactly where they have been removed (i.e., the foraging area or a glass tube).

\section{Results}

3.1. Foragers (Table 1, Upper Left Part). Foragers did not at all follow a line imbibed with pure hexane. On the contrary, 
they well walked along a line imbibed with the species' trail pheromone $(P<0.001)$. The results obtained for nest I and nest II were similar.

\subsection{Naive Young Workers (Table 1, Upper Right Part). Naive} young ants did not follow a blank circumference, moving in its surrounding as usual. They also did not follow a circumference imbibed with the trail pheromone but came on it, seemed to perceive the pheromone, and sometimes walked along a few arcs along it. However, the young ants' trail following statistically stayed inefficiently (NS). Such a result was similarly obtained for nests I and II.

3.3. Foragers and Naive Ants in Presence of One Another (Table 1, Lower Left Part). As expected, no aggressive behavior was observed in such groups of ants. Thanks to the marking of the older ants, the two kinds of ants could be separately observed. The older ones went on following the trail, as previously $(P<0.001)$. They were observed to contact younger ants and often to walk before them. The young ones contacted the older ones, moved on the trail, followed older ants, and finally walked rather well along the trail. Their trail following behavior was then statistically different from their control trajectory $(P<0.01)$ though being not yet identical to that of older workers $(P<0.01)$. Experiments made on nest I and nest II were in agreement.

3.4. Young Ants after Having Been in Presence of Older Congeners on a Trail (Table 1, Lower Middle Part). The young ants of nest I that had been in presence of trail following foragers were again tested after a $20 \mathrm{hrs}$ time period. They appeared to better follow the trail than when they were moving together with their older nestmates. Their trail following behavior was statistically significant $(P<0.01)$ and only slightly different from that of their older congeners $(P<0.05)$. The young ants of nest II which had been in presence of trail following older ants were again tested after a $2 \mathrm{hrs}$ time period: their behavior was unchanged (NS). They were tested once more after a 24 hrs time period: their trail following was then of better quality; it was statistically different from a control movement $(P<0.01)$ and, this time, similar to that of older ants (NS). Note that 20-24 hrs are usual time periods for obtaining some learning in Myrmica spp. workers [8-10, 13].

3.5. Queens (Table 1, Lower Left Part). The queens were tested individually, one by one, on a different but chemically identical trail. When a queen reached for the first time the trail, it hesitated, then crossed the trail, came back to it, crossed it again, and after a few minutes began to walk along the trail. Each queen firstly followed the trail along a short distance, then along about 8-12 10 ang. deg. arcs, and then along a very variable distance according to the tested queen. Two of the tested queens followed the trail along about 1510 ang. deg. $\operatorname{arcs}(=15 \times 31.4 / 36=13.1 \mathrm{~cm})$. The third one never stopped to walk along the trail, its numbers of 10 ang. deg. arcs walked arcs equaling successively 60, 90 then largely more than 100 . That queen was then removed from the trail and gently set back inside of its nest tube. The tested queens behaved thus similarly in front of a trail (recognition of the pheromone, knowledge of its signification, and trail following exhibition), but their trail following score largely differed.

\section{Discussion}

Contrary to foragers, young ants do not efficiently follow a trail though they obviously perceive the pheromone. This is in agreement with previous results [19]. Set in presence of trail following foragers, the young ants begin to better follow a trail. Thereafter, their performance increases in the course of time, so that they become able to efficiently follow a trail without the presence of older congeners. The trail following behavior is thus partly native and very probably also partly improved thanks to true learning. Such learning may be induced and/or enhanced by older trail following nestmates. However, though results are very suggestive of learning, they do not demonstrate this unequivocally. An unequivocal proof could be obtained by testing old ants having never encountered a trail. The fact that the knowledge of the trail pheromone and at least partly the trail following behavior are native is confirmed by the behavior of queens removed from the nest and set on a trail: they follow the trail with variable score.

Future queens may acquire the information relative to the trail pheromone before they leave their parental colony. They may walk on the foraging area, then return back to their nest perceiving and being helped by the trail pheromone. They may then more or less learn to follow a trail. Each future founder queen may acquire, with variable score, the knowledge of the species' pheromones (and other characteristics). After that, during their life, founder queens have the opportunity to follow a trail when their colony relocates.

At a phylogenic point of view, on the basis of the behavior of old and young ants set together on a trail, it may be presumed that the trail following behavior derived from the more primitive tandem running behavior described, for instance, by Agbogba [23]. The species Manica rubida, more primitive than the Myrmica ones, should be studied as for this point of view, with the advantage that its trail pheromone is chemically identical to that of several species of Myrmica [24].

There exists a very large quantity of works dealing with the glandular origin of the trail pheromone [25-28], the usefulness of a chemical trail $[1,29-31]$, what such a chemical trail may inform [32-35], its chemical identification ([27, page 269], [20]) and with different aspects concerning the ants' trail and trail following behavior (e.g., [1, 28, 36-38]). But there is presently no study concerning the ontogenesis of the trail following behavior (except an old work showing that young ants cannot well follow a trail [19]).

\section{Conclusion}

The present work explains, at least partly and on one ant species, the ontogenesis of the workers' trail following behavior (native knowledge of the pheromone and, at least partly, learning of the behavior) and proposes a phylogenetic origin for this behavioral trait. 


\section{Acknowledgment}

The author is very grateful to Dr. T. Sullivan for having copyedited this paper.

\section{References}

[1] L. Passera and S. Aron, Les Fourmis: Comportement, Organisation Sociale et Évolution, Les Presses Scientifiques du CNRC, Ottawa, Canada, 2005.

[2] M.-C. Cammaerts, R. P. Evershed, and E. D. Morgan, "Comparative study of the mandibular gland secretion of four species of Myrmica ants," Journal of Insect Physiology, vol. 27, no. 4, pp. 225-231, 1981.

[3] E. D. Morgan, R. C. Tyler, and M.-C. Cammaerts, "Identification of the components of the Dufour's gland secretion of the ant Myrmica rubra L. and their behavioural responses," Journal of Insect Physiology, vol. 23, pp. 511-515, 1977.

[4] S. Mayade, M.-C. Cammaerts, and J.-P. Suzzoni, "Home-range marking and territorial marking in Cataglyphis cursor (Hymenoptera, Formicidae)," Behavioural Processes, vol. 30, no. 2, pp. 131-142, 1993.

[5] M.-C. Cammaerts and R. Cammaerts, "Marking of nest entrances and their vicinities in the ant Myrmica rubra," Biologia, vol. 54, no. 5, pp. 553-566, 1999.

[6] R. P. Evershed, E. D. Morgan, and M.-C. Cammaerts, “3-ethyl2,5-dimethylpyrazine, the trail pheromone from the venom gland of eight species of Myrmica ants," Insect Biochemistry, vol. 12, no. 4, pp. 383-391, 1982.

[7] R. Hamidi, S. Aron, and J.-C. de Biseau, "Le profil d'hydrocarbures cuticilaires signale-t-il la présence d'une reine fécondée chez la fourmi Camponotus lateralis?" Actes des Colloques de L'IUSSI, vol. 16, pp. 30-35, 2004.

[8] M.-C. Cammaerts and Z. Rachidi, "Olfactive conditioning and use of visual and odorous cues for movement in the ant Myrmica sabuleti (Hymenoptera, Formicidae)," Myrmecological News, vol. 12, pp. 117-127, 2009.

[9] M.-C. Cammaerts, Z. Rachidi, S. Beke, and Y. Essaadi, "Use of olfactory and visual cues for orientation by the ant Myrmica ruginodis (Hymenoptera, Formicidae)," Myrmecological News, vol. 16, pp. 45-55, 2012.

[10] M.-C. Cammaerts, "Navigation system of the ant Myrmica rubra (Hymenoptera, Formicidae)," Myrmecological News, vol. 16, pp. 111-121, 2012.

[11] A. Bonavita-Cougourdan and L. Morel, "Les activités antennaires au cours des contacts trophallactiques chez la fourmi Camponotus vagus scop. Ont-elles valeur de signal?” Insectes Sociaux, vol. 31, pp. 113-131, 1984.

[12] L. P. Casacci, J. A. Thomas, M. Sala et al., "Ant pupae employ acoustics to communicate social status in their colony's hierarchy," Current Biology, vol. 23, pp. 323-327, 2013.

[13] M. C. Cammaerts, "Age dependent spatio-temporal learning in the ant Myrmica sabuleti (Hymenoptera, Formicidae)," Buletin de la Société Royale Belge D’Entomologie, 2014.

[14] M.-C. Cammaerts and D. Cammaerts, "Comparative outlook over three Myrmica species' biotopes and foragers' know-how," Biologia. In press.

[15] N. Bos and P. D.'Ettorre, "Recognition of social identity in ants," Psychology, vol. 3, article 83, 2012.

[16] M.-C. Cammaerts, "Ants' learning of nest entrance characteristics (Hymenoptera, Formicidae)," Bulletin of Entomological Research, 2013.
[17] M.-C. Cammaerts, "Ants' learning of their foraging area specific marking odor (Hymenoptera, Formicidae)," Journal of Entomological Research. Submitted.

[18] M.-C. Cammaerts-Tricot, "Piste et phéromone attractive chez la fourmi Myrmica rubra," Journal of Comparative Physiology, vol. 88, pp. 373-338, 1974.

[19] M.-C. Cammaerts-Tricot and J.-C. Verhaeghe, "Ontogenesis of trail pheromone production and trail following behaviour in the workers of Myrmica rubra L. (Formicidae)," Insectes Sociaux, vol. 21, no. 3, pp. 275-282, 1974.

[20] R. P. Evershed, E. D. Morgan, and M.-C. Cammaerts, "Identification of the trail pheromone of the ant Myrmica rubra L., and related species," Naturwissenschaften, vol. 68, no. 7, pp. 374-376, 1981.

[21] M.-C. Cammaerts, "Etude démograpique annuelle des sociétés de Myrmica rubra L. des environs de Bruxelles," Insectes Sociaux, vol. 24, pp. 147-161, 1977.

[22] S. Siegel and N. J. Castellan, Nonparametric Statistics For the Behavioural Sciences, McGraw-Hill Book Company, Singapore, 1989.

[23] C. Agbogba, "Observations sur le comportement de marche en tandem chez deux espèces de fourmis ponérines: Mesoponera caffraria (Smith) et Hypoponera sp. (Hym. Formicidae)," Insectes Sociaux, vol. 31, pp. 264-276, 1984.

[24] A. B. Attygalle, M.-C. Cammaerts, R. Cammaerts, V. Lancaster, and E. D. Morgan, "Chemical and ethological studies of the trail pheromone of the ant Manica rubida (Hymenoptera, Formicidae)," Physiological Entomology, vol. 11, pp. 125-132, 1986.

[25] R. H. Leuthold, "A tibial gland scent-trail and trail laying behavior in the ant Crematogaster ashmeadi Mayr," Psyche, vol. 75, pp. 233-248, 1968.

[26] M. C. Cammaerts-Tricot, E. D. Morgan, and R. C. Tyler, "Isolation of the trail pheromone of the ant Myrmica rubra," Journal of Insect Physiology, vol. 23, no. 3, pp. 421-427, 1977.

[27] B. Hollobler and E. O. Wilson, The Ants, Harvard University Press, Springer, 1990.

[28] J. Billen and E. D. Morgan, "Pheromone communication in social insects-sources and secretions," in Pheromone Communication in Social Insects: Ants, Wasps, Bees, and Termites, R. K. V. Meer, M. D. Breed, K. E. Espelie, and M. L. Winston, Eds., p. 3, Westview Press, Boulder, Colo, USA, 1998.

[29] M. Cammaerts-Tricot -C, "Recrutement d'ouvrières, chez Myrmica rubra, par les phéromones de l'appareil à venin," Behaviour, vol. 50, no. 1-2, pp. 111-122, 1974.

[30] B. Hölldobler, "Recruitment behavior in Camponotus socius (Hym. Formicidae)," Zeitschrift für Vergleichende Physiologie, vol. 75, no. 2, pp. 123-142, 1971.

[31] B. Holldobler and E. O. Wilson, "Recruitment Trails in the Harvester Ant Pogonomyrmex badius," Psyche, vol. 77, pp. 385-399, 1970.

[32] W. Hangartner, "Structure and variability of the individual odor trail in Solenopsis geminata Fabr. (Hymenoptera, Formicidae)," Zeitschrift für Vergleichende Physiologie, vol. 62, no. 1, pp. 111$120,1969$.

[33] E. O. Wilson, "Chemical communication among workers of the fire ant. Solenopsis saevissima (Fr Smith). 1. The organization of mass-foraging," Animal Behaviour, vol. 10, no. 1-2, pp. 134-147, 1962.

[34] E. O. Wilson, "Chemical communication among workers of the fire ant Solenopsis saevissima (Fr. Smith). 2. An information analysis of the odour trail," Animal Behaviour, vol.10, no. 1-2, pp. 148-158, 1962. 
[35] E. O. Wilson, "Chemical communication among workers of the fire ant. Solenopsis saevissima (Fr Smith). 3: The experimental induction of social responses," Animal Behaviour, vol. 10, no. 1-2, pp. 159-164, 1962.

[36] C. Detrain, J. M. Pasteels, and J. L. Deneubourg, "Polyéthisme dans le trace et le suivi de la piste chez Pheidole pallidula (Formicidae)," Actes des Colloques de L'IUSSI, vol. 4, pp. 87-94, 1988.

[37] C. Devigne and C. Detrain, "Effet de la distance sur le recrutement alimentaire chez la fourmi Lasius niger (L.)," Actes des Colloques de L'IUSSI, vol. 12, pp. 79-85, 1999.

[38] C. Detrain, O. Tasse, M. Versaen, and J. M. Pasteels, "A field assessment of optimal foraging in ants: trail patterns and seed retrieval by the European harvester ant Messor barbarus," Insectes Sociaux, vol. 47, no. 1, pp. 56-62, 2000. 

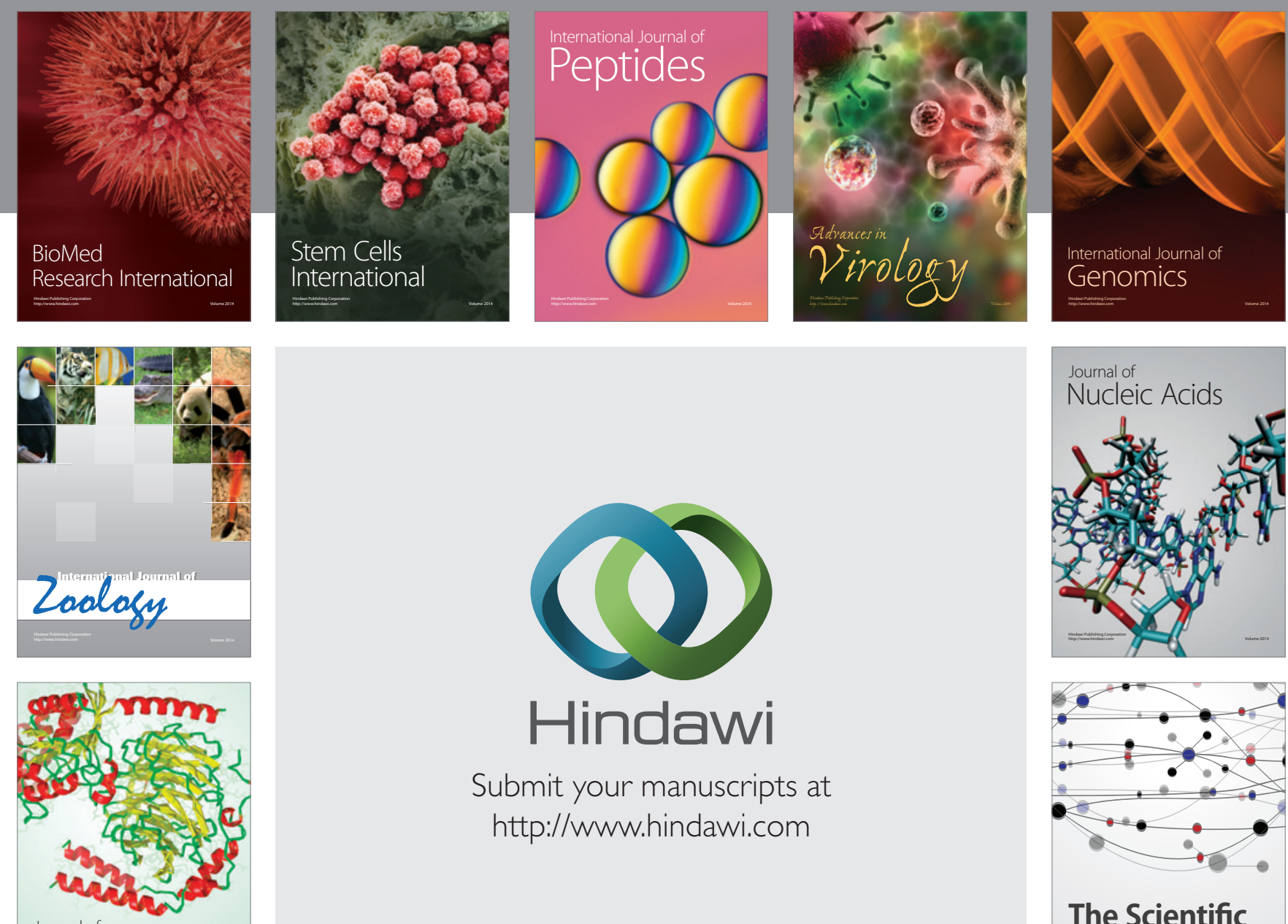

Submit your manuscripts at

http://www.hindawi.com

Journal of
Signal Transduction
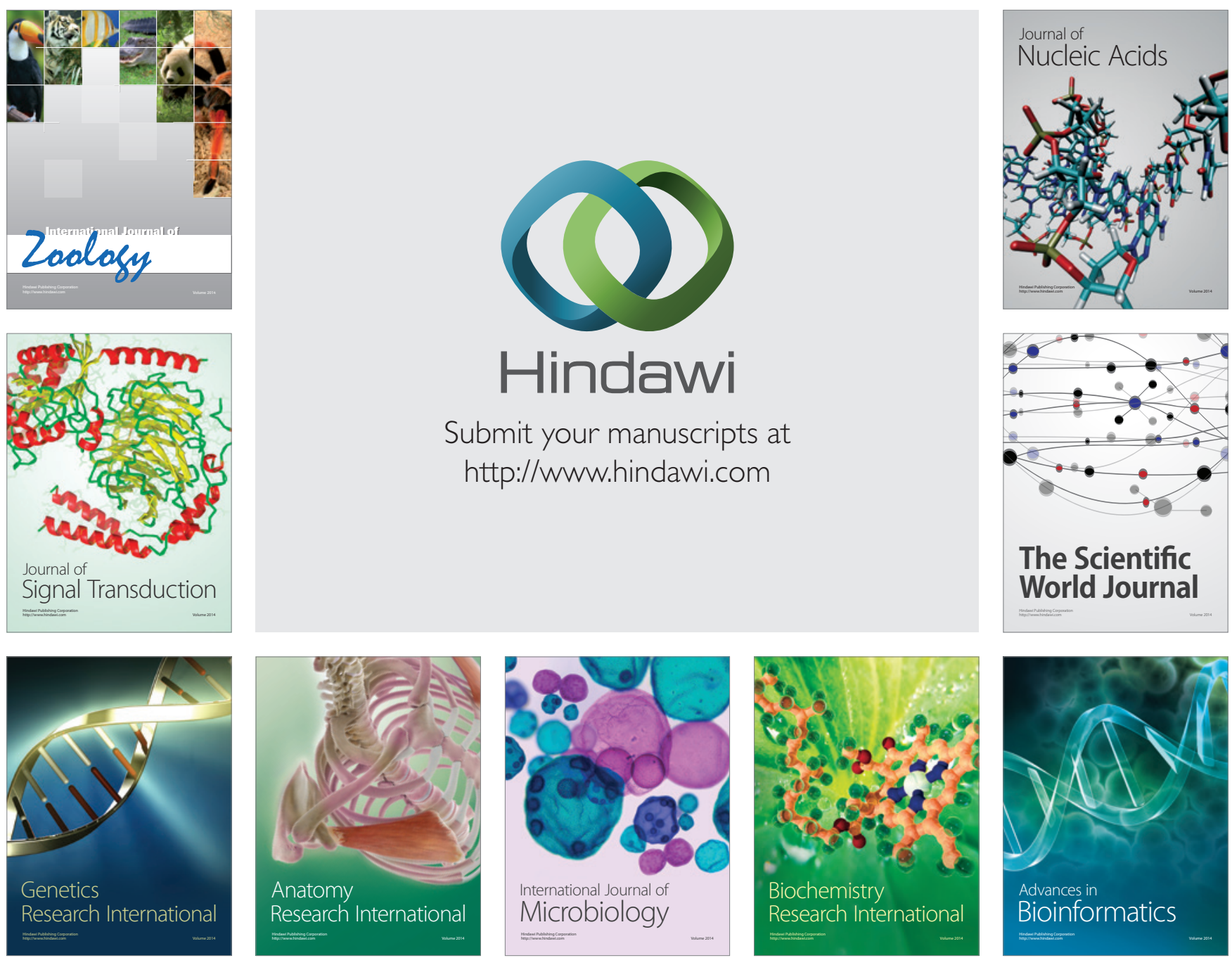

The Scientific World Journal
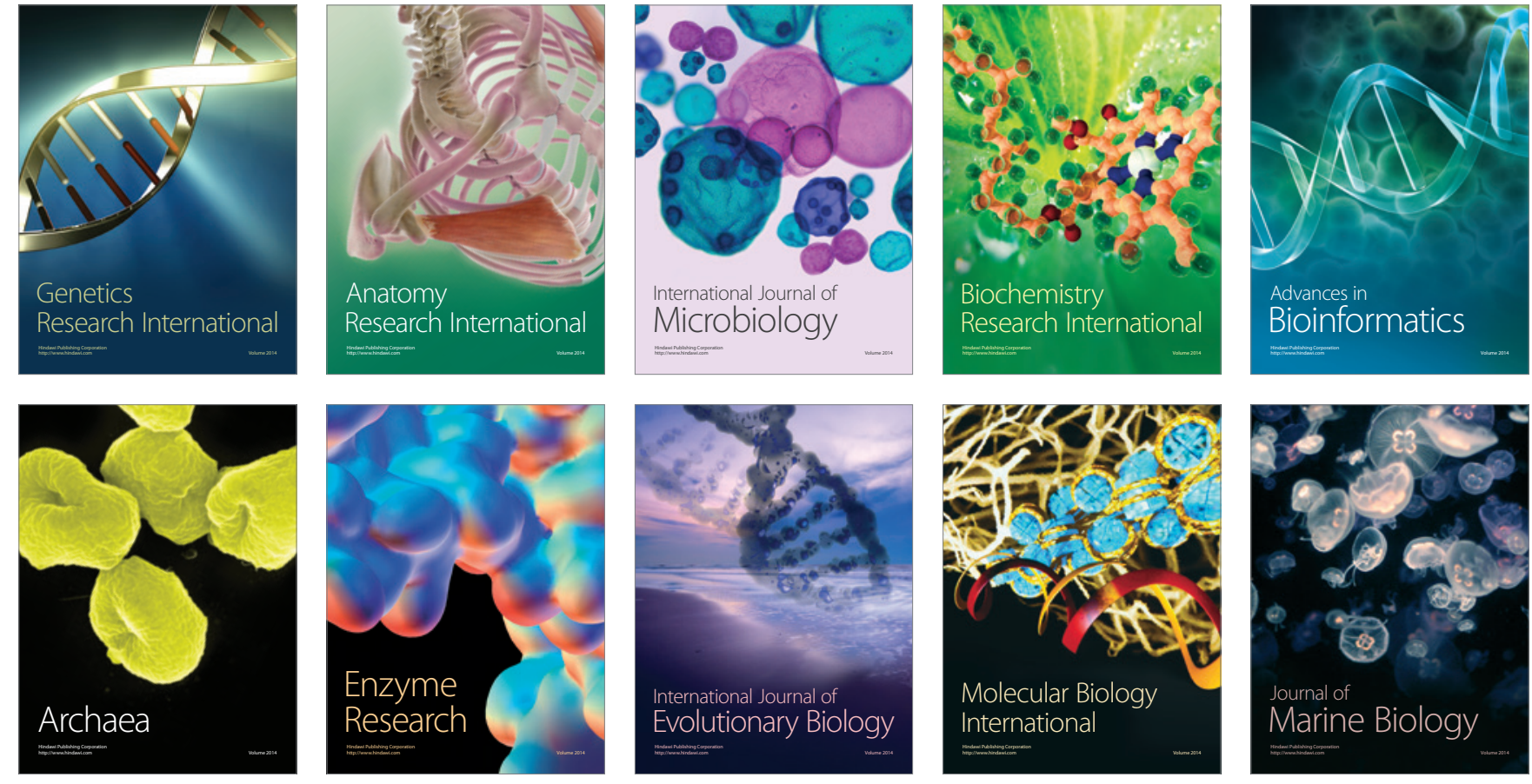